\title{
Ketebalan kulit bumi dan struktur kecepatan antara hiposenter gempa M012601A dan stasiun AAK
}

\author{
Bagus Jaya Santosa* \\ Jurusan Fisika, FMIPA, Institut Teknologi Sepuluh Nopember, \\ Kampus ITS Sukolilo, Surabaya 60111
}

\begin{abstract}
Intisari
Gempa M012601A terletak di India Utara dan stasiun AAK di Kirgistan, topografi antara kedua titik berbentuk pegunungan, yaitu Himalaya. Penelitian ini menginvestigasi struktur kecepatan di daerah kompleks pegunungan tersebut melalui fitting seismogram. Seismogram observasi dibandingkan dengan seismogram sintetik dalam domain waktu dan ke tiga komponen Kartesian secara simultan. Seismogram sintetik dihitung dengan program GEMINI, dimana input awalnya adalah model bumi global IASPEI91 dan PREMAN. Selain itu pada kedua seismogram dikenakan low-pass filter dengan frekuensi corner pada $20 \mathrm{mHz}$.

Analisa seismogram menunjukkan penyimpangan yang sangat kuat pada pengamatan atas waktu tiba, jumlah osilasi dan tinggi amplitudo, pada gelombang permukaan Love dan Rayleigh dan gelombang ruang $\mathrm{S}$ dan $\mathrm{P}$.

Untuk menyelesaikan simpangan yang dijumpai diperlukan koreksi atas struktur bumi. Fitting seismogram diperoleh dengan baik pada waveform fase gelombang, baik waktu tempuh osilasi utama dan jumlah osilasi.

Hasil riset ini menunjukkan, bahwa daerah pegunungan Himalaya mempunyai ketebalan kulit bumi sebesar $42 \mathrm{~km}$, hasil ini diperoleh melalui fitting pada Love waveform.
\end{abstract}

KATA KUNCI: Analisa Seismogram, Model Kecepatan S dari Upper Mantle - CMB, Pegunungan Himalaya

\section{PENDAHULUAN}

Gempa M012601A adalah gempa dengan kekuatan 6,0 skala Richter, yang terjadi di India Utara pada tanggal 26 Januari 2001 dengan kedalaman sumber gempa $20 \mathrm{~km}$. Letak hiposenter di selatan daerah Pegunungan Himalaya dan stasiun observasi AAK terletak di sebelah utara Pegunungan Himalaya, letaknya hampir persis utara terhadap episenter gempa, sehingga gelombang merambat sepenuhnya di bawah kompleks pegunungan Himalaya.

Berikut ini disajikan tinjauan geologi dari terbentuknya Pegunungan Himalaya. Secara umum, pegunungan tinggi seperti Himalaya dihasilkan oleh pendekatan pertumbuhan dari pelat-pelat lithosfer utama, sebagaimana penyisipan fragmen pelat-pelat kecil dan pulau-pulau di pinggiran benua, dari skala waktu geologi Mesozoik akhir hingga kini. Pecahnya Permo Carboniferous di super benua Pangea dan terbentuknya Lautan Tethys antara Karibia dan area Himalaya menghasilkan formasi dalam bentuk sejumlah kecil blok-blok benua, area yang luas atas laut dangkal di tepi-tepi benua, dan pinggiran benua yang terpecah-pecah dan menjadi tertimbun oleh deretan karbonat yang tebal selama masa Triasik dan Jurrasik. Perubahan arah pergerakan terjadi pada masa Kretaseous, basin-basin lautan utama dibatasi oleh subduksi dari lithosfer oseanik, bekas dari kulit bumi lautan terangkat ke atas, hingga kedua fragment benua yang kecil dan besar bertumbukan membentuk setumpukan lapisan atas marginmargin tipis di pinggir benua, proses metamorfosis berjalan pada skala yang luas dan pegunungan-pegunungan tinggi ter-

\footnotetext{
*E-MAIL: bjs@physics.its.ac.id
}

bentuk di beberapa tempat. Rantai pegunungan Himalaya yang spektakuler dan ditetangganya yang berupa relief tinggi yaitu di Plateau Tibet dihasilkan oleh tumbukan antara pelat anak benua India dengan margin benua Asia dan pelat-pelat kecil yang menyusup yang dimulai 50 Mtahun lalu dan masih berlangsung hingga kini. Ini ditandai dengan gempa-gempa bumi yang masih sering terjadi di daerah ini dan salah satunya yaitu gempa M012601A yang seismogramnya akan dianalisa dalam riset ini.

Gempa bumi membangkitkan pergerakan tanah di hampir semua tempat di permukaan bumi. Getaran/Pergerakan tanah dapat diukur melalui seismometer di stasiun penerima. Seismometer mengubah kecepatan atau percepatan pergerakan tanah dalam dimensi $\left[\mathrm{mm} / \mathrm{dt}\right.$ atau $\left.\mathrm{mm} / \mathrm{dt}^{2}\right]$ menjadi dimensi tegangan listrik $(\mathrm{mV})$, dan direkam sebagai deret waktu berupa bilangan digital. Rekaman ini dapat disajikan kembali sebagai seismogram.

Ada dua metoda yang hingga kini masih intensif digunakan oleh para seismolog untuk analisa kuantitatif atas seismogram. Pertama adalah catatan atas waktu-waktu tiba fase gelombang utama, dan kedua catatan atas hubungan antara kecepatan fase dengan perioda pada gelombang permukaan, yang disebut sebagai analisa dispersi. Dua metoda kuantitatif yang digunakan di atas hanya mengevaluasi sedikit informasi tertentu dalam sebuah deret waktu seismogram.

Dari catatan waktu tiba fase gelombang yaitu utama atas data waktu-waktu tiba gelombang P dan sedikit data waktuwaktu tiba gelombang $\mathrm{S}$, struktur kecepatan perambatan gelombang $\mathrm{P}(\alpha)$ dan $\mathrm{S}(\beta)$ dapat diinterpretasikan melalui aplikasi atas teori inversi. Karena jumlah data waktu tempuh gelombang $\mathrm{P}$ jauh lebih banyak daripada jumlah data waktu tempuh gelombang $\mathrm{S}$, resolusi dari struktur kecepatan $\mathrm{P}$ juga lebih baik daripada struktur kecepatan S. Dari himpunan data 
waktu tempuh yang diperoleh dengan mencatat waktu tiba yang direkam oleh stasiun-stasiun yang tersebar di seantero permukaan bumi atas ribuan gempa dan dalam rentang waktu yang lama, sebuah model bumi global seperti PREM, PREMAN (versi vertikal anisotrop dari PREM) [7] dan IASPEI91 [10] dapat ditentukan.

Dari model bumi global dapat dikembangkan lebih lanjut untuk mendapatkan model bumi regional di daerah Pegunungan Himalaya, melalui penggelaran stasiun-stasiun observasi di sekitar daerah-daerah sumber gempa $[11,12]$. Melalui aplikasi atas teori inversi pada data waktu tempuh di stasiunstasiun observasi di sekitar sumber gempa, didapatkan struktur bumi regional yang lebih detil di bawah daerah yang diteliti. Hasil tomografi struktur bumi adalah hanya kecepatan penjalaran gelombang $\alpha$ dan $\beta$. Untuk mendapatkan parameter elastik batuan penyusun bumi, digunakan metoda normal mode dan analisa dispersi. Riset-riset seismolog di daerah ini umumnya menggunakan metoda analisa dispersi dan receiver function, dimana hubungan antara kecepatan fase terhadap perioda pada gelombang permukaan di masing-masing komponen gerak adalah data sekunder. Data dispersi diinversikan untuk mendapatkan struktur anisotropi dan heterogenitas di sekitar bawah Pegunungan Himalaya [4, 5, 13].

Masalah yang dihadapi dalam riset ini adalah : Bagaimanakah mendiskripsikan model kulit bumi di bawah daerah Pegunungan Himalaya, dengan model kulit bumi benua standard atau yang lebih tebal ? Selain itu akan diteliti bagaimana reaksi waveform terhadap model-model kulit bumi ini dan bagaimanakah struktur kecepatan $\mathrm{S}$ di daerah ini, dengan memanfaatkan analisa seismogram.

\section{METODOLOGI PENELITIAN}

Data seismogram dapat diperoleh dari Databank Center IRIS (HTTP : dmc.iris.washington.edu), yang datanya dapat diakses per internet. Setiap gempa menghasilkan pergerakan tanah, yang oleh sebuah stasiun akan direkam dalam arah ketiga komponen Kartesian (N-S, E-W and vertical Z, lokal pada kedudukan stasiun penerima, dikenal sebagai kanal dengan akhiran $-\mathrm{E}-\mathrm{N} \&-\mathrm{Z}$ ). Kedudukan sumber gempa adalah di India Utara, dengan koordinat $23,42^{0}$ Lintang Utara dan $70,23^{0}$ Bujur Timur sedangkan stasiun observasi AAK terletak pada $42,64^{0}$ Lintang Utara dan $74,49^{\circ}$ Bujur Timur. Untuk memisahkan komponen pergerakan tanah dalam arah toroidal dan radial, bidang horisontal yang dibentuk oleh garis N-S dan E-W lokal di stasiun observasi harus diputar, sedemikian hingga arah 'Utara' lokal diarahkan pada arah busur kecil dari stasiun observasi AAK ke arah episenter gempa (arah back-azimuth), lihat gambar 1. Pengubahan arah diperlukan untuk memisahkan gelombang dalam ruang 3-dimensi menjadi komponen-komponen penjalaran gelombang dalam mode gelombang P-SV dan SH.

Pertama dalam penelitian ini harus dijalankan program komputer untuk melaksanakan perhitungan atas waktu tempuh sintetik fase-fase gelombang ruang utama, yaitu program TTIMES yang dibuat berdasarkan makalah dari Bulland \& Chapman [3], didapat dari http://orfeus.knmi.nl. Program

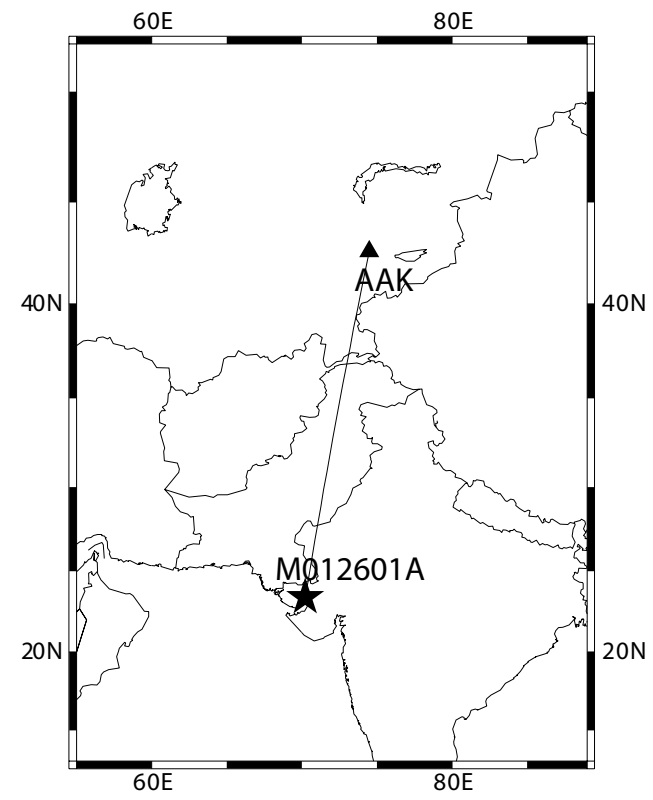

Gambar 1: Jalan Gelombang dari Episenter hingga Stasiun Observasi AAK

ini tak dapat menghitung waktu tempuh dari gelombang permukaan, karena metoda rambat mode gelombang ini mendatar sepanjang permukaan bumi dan menjangkau kedalaman tertentu yang setara dengan panjang gelombangnya [8].

Untuk memproduksi seismogram sintetik dari gempa tersebut di stasiun observasi digunakan program yang berbasis metoda GEMINI (Green's function of the Earth by MINor Integration) $[2,9]$. Program GEMINI (Green's function of the Earth by MINor Integration) adalah menghitung minor dari fungsi-fungsi Green's atas suatu model bumi dan untuk suatu kedalaman sumber gempa tertentu. di mana fungsi-fungsi Green's diekspansikan untuk memenuhi kondisi syarat batas di titik terdalam gelombang, titik kedalaman sumber dan permukaan bumi. Ekspansi dituliskan dalam frekuensi komplex, dengan memasukkan trick damping untuk menghindari time aliasing. Seismogram sintetik ditransformasikan dari domain frekuensi komplex ke domain waktu, dimana sebelumnya dikenakan filter lolos rendah Butterworth dan RESPONSE file dari sistim peralatan seismometer di stasiun penerima, yaitu deskripsi tentang perubahan fase dan amplifikasi dari sistim peralatan ketika mengubah input dalam kecepatan/ percepatan pergerakan tanah menjadi output tegangan $[\mathrm{mV}]$, sehingga seismogram sintetik dan seismogram riil dibandingkan dalam dimensi yang sama.

Ketika program ini dijalankan, haruslah sebuah model bumi diberikan sebagai input awal, yaitu model bumi IASPEI91 dan PREMAN. Sebagai model bumi masukan, data harus mengandung parameter elastik secara lengkap, yaitu meliputi kecepatan penjalaran gelombang kompresi dan shear dari batuan penyusun struktur bumi.

Jumlah data dalam komparasi seismogram pada tiga komponen adalah ribuan, sehingga perubahan ketebalan kulit 


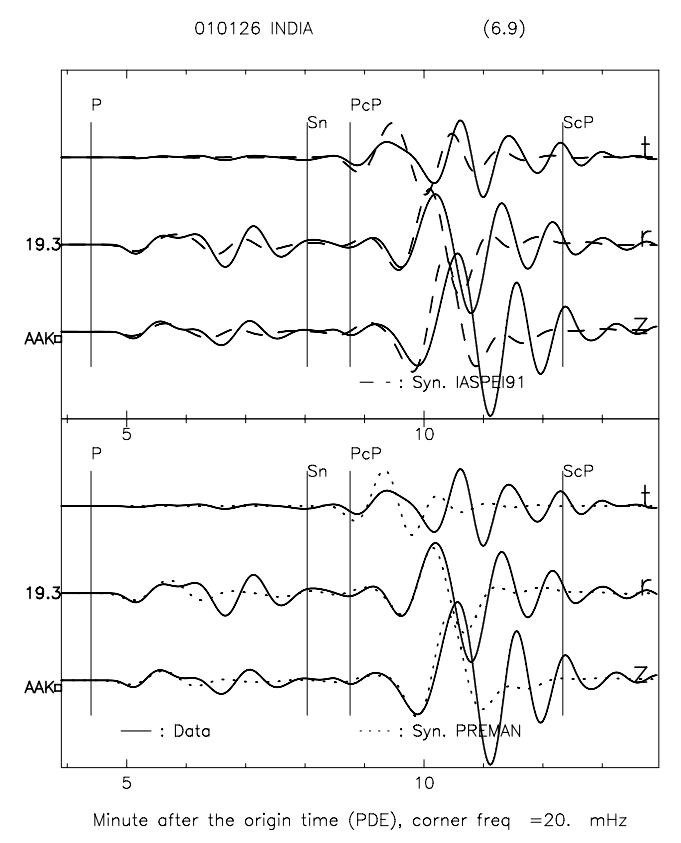

Gambar 2: Perbandingan seismogram terukur dengan sintetiksintetiknya dari model-model bumi standard di stasiun AAK

bumi, gradient kecepatan, dan besar koefisien awal fungsi polinomial kecepatan di tiap lapisan bumi dilakukan melalui metoda trial and error,

\section{ANALISA DAN PEMBAHASAN}

Dalam penelitian ditampilkan analisa sebuah gempa India Utara, 26 Januari 2001, yang gelombangnya ditangkap oleh stasiun observasi seismologi AAK, Kirgistan.

Pertama akan disajikan analisa seimogram antara seismogram terukur dengan sintetik-sintetiknya, yang masingmasing dihitung dari model bumi standard IASPEI91 yang isotrop ( 3 trace atas) dan PREMAN yang vertikal anisotropy (3 trace bawah).

Pada gambar 2 dapat dilihat perbedaan antara seismogram riil dengan sintetiknya yang terjadi baik pada travel time atau bentuk waveform secara keseluruhan, yaitu tinggi amplitudo dan jumlah osilasi. Jarak episentral stasiun AAK adalah $19,3^{0}$, sehingga gelombang-gelombang $\mathrm{S}$ dan repetisinya tertumpuk di awal gelombang permukaan Love yang memiliki amplitudo besar. Oleh karena itu penentuan waktu tiba fase $\mathrm{S}$ pada jarak episentral kecil tidak mudah, karena waveform $\mathrm{S}$ berinterferensi dengan waveform Love. Kita dapat melihat, bahwa solusi CMT [6] tidak memanfaatkan perbedaan ketebalan kulit bumi di berbagai belahan bumi, bahkan di region hiposenter gempa sekalipun. Dalam perhitungan CMT digunakan model bumi dengan sebuah struktur kulit bumi yang tunggal. Model bumi bumi IASPEI91 yang isotrop memberikan gelombang Love sintetik yang sedikit lebih cocok pada gelombang Love riil, meskipun amplitudonya masih

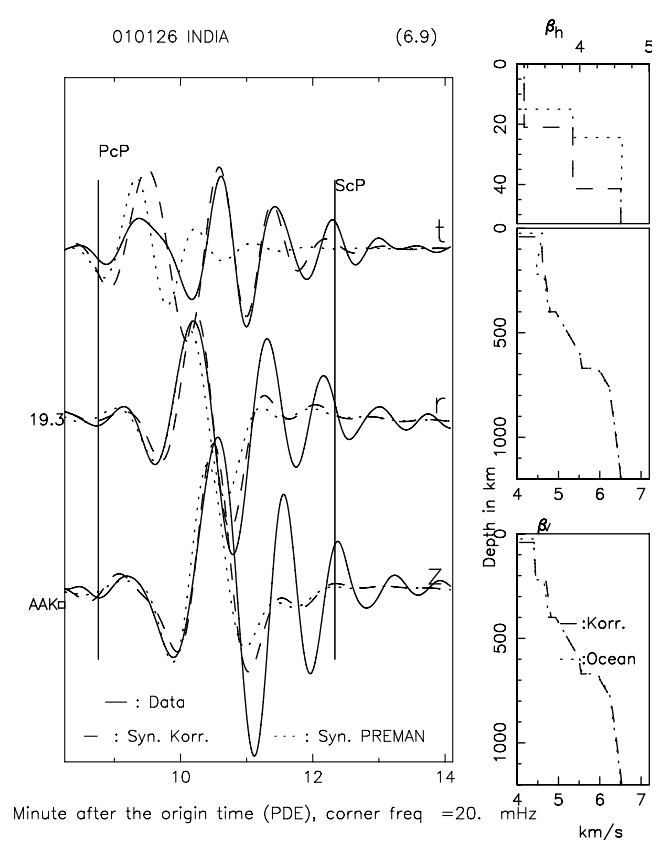

Gambar 3: Perbandingan seismogram terukur dengan sintetik dikoreksi untuk jendela waktu gelombang Love di stasiun AAK, frek. sudut $20 \mathrm{mHz}$

sedikit lebih kecil dan meluruh lebih cepat serta tiba lebih awal. Pengamatan pada komponen yang lain, $\mathrm{z}$ dan $\mathrm{r}$, dimana dapat dilakukan pada gelombang permukaan Rayleigh yang menunjukkan bahwa Rayleigh sintetik memiliki osilasi yang lebih pendek daripada gelombang Rayleigh riil dengan osilasi panjang dan tiba lebih awal pula daripada waveform Rayleigh terukur pada maksimum pertama. Umumnya riset seismologi yang menggunakan metoda analisa dispersi justru senang dengan memanfaatkan data gelombang Rayleigh terukur seperti ini (memiliki osilasi yang panjang), dimana kurva dispersi didapatkan mempunyai spektrum yang lebih lebar. Model bumi PREMAN memberikan seismogram sintetik yang lebih buruk lagi, terjadi pada gelombang permukaan Love. Gelombang Love sintetik memiliki jumlah osilasi juga lebih pendek.

Model bumi PREMAN dan IASPEI91 mempunyai perbedaan ketebalan kulit bumi sebesar $10 \mathrm{~km}(25 \mathrm{~km}$ dan 35 $\mathrm{km}$ ), dan perbedaan ketebalan ini diperjelas dengan waveform gelombang Love. Walaupun panjang gelombang adalah sekitar $150 \mathrm{~km}$, perbandingan waveform menunjukkan kepekaan waveform Love terhadap struktur kulit bumi.

Model bumi IASPEI91 dibentuk hanya dari data waktu tempuh dan memiliki sifat isotrop. Padahal pengamatan menunjukkan bahwa diskrepansi waveform terjadi pada ke tiga komponen dan ini tidak dapat diselesaikan dengan pengandaian model bumi yang isotrop. Untuk selanjutnya, perbandingan seismogram didasarkan pada seismogram sintetik yang dibangun dari model bumi PREMAN dan model bumi dikoreksi, dimana ketebalan kulit bumi pada model IASPEI91 digunakan sebagai initial model bumi dikoreksi.

Gambar 3 menunjukkan fitting seismogram pada gelombang permukaan Love yang terjadi baik pada travel time 


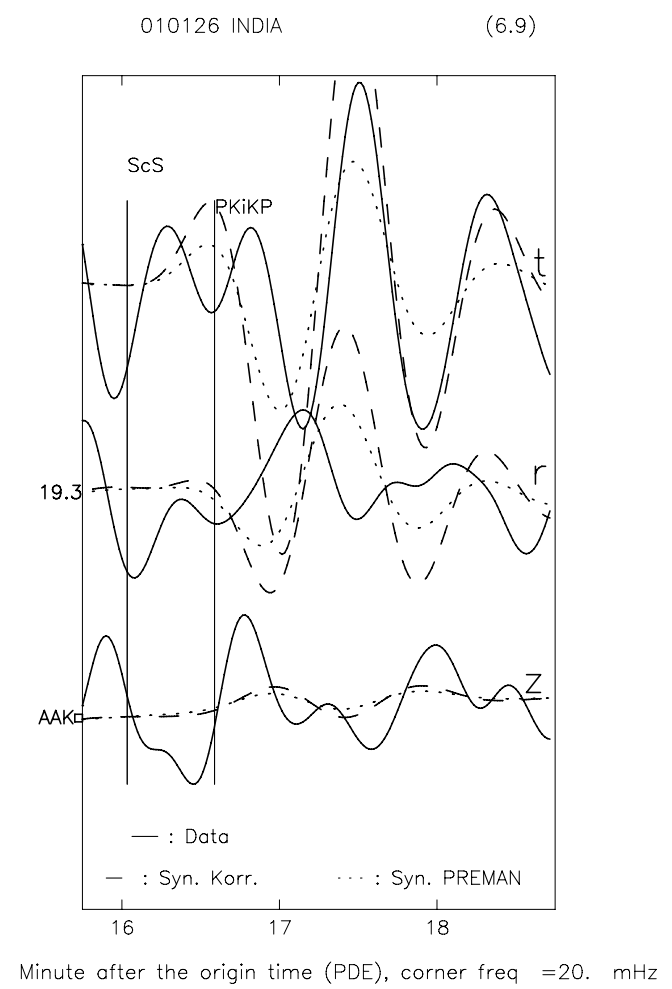

Gambar 4: Perbandingan seismogram terukur dengan sintetik dikoreksi untuk jendela waktu gelombang $\mathrm{ScS}$ di stasiun $\mathrm{AAK}$, frek. sudut $20 \mathrm{mHz}$

ataupun jumlah osilasi. Dalam gambar ini, garis mulus adalah data dan garis terpenggal adalah kurva sintetik dikoreksi. Fitting dilakukan dengan memasang gradien positif untuk kecepatan $\beta_{h}$ di upper mantle dan dengan mengubah-ubah ketebalan kulit bumi. Prosedur ini dilakukan secara iteratif dengan mengamati seismogram sintetik, apakah telah memberikan fitting yang baik pada seismogram terukur ? Kereta gelombang Love dari model bumi PREMAN (dengan kurva titiktitik) mengsimulasikan dengan baik waktu tiba amplitudo pertama, namun dengan cepat meluruh. Dengan tebal kulit bumi $42 \mathrm{~km}$ dan gradien struktur kecepatan $\beta_{h}$ menjadi positif di lapisan upper mantle [1] diperoleh fitting yang sangat baik pada gelombang Love, hingga gelombang keempat. Sedangkan perbaikan pada gelombang Rayleigh dilaksanakan dengan koreksi yang juga bernilai positif di lapisan-lapisan dalam bumi di bawah Upper mantle. Ketebalan kulit bumi sebesar $42 \mathrm{~km}$ dapat dilihat pada kotak gambar di sisi kanan yang paling atas, dimana disajikan struktur kecepatan gelombang $\beta_{h}$ di dekat permukaan bumi.

Gambar 4 merepresentasikan fitting seismogram pada jendela waktu gelombang $\mathrm{ScS}$, yaitu gelombang yang dipancarkan sumber gempa dalam arah sinar ke bawah hingga gelombang menjumpai antarmuka CMB (Core Mantle Boundary) dan terpantul balik ke permukaan bumi dan ditangkap oleh stasiun observasi AAK. Memang pada osilasi utama gelombang sintetik dikoreksi memberikan amplitudo sedikit lebih besar, namun fitting pada osilasi akhir terlihat sangat bagus,

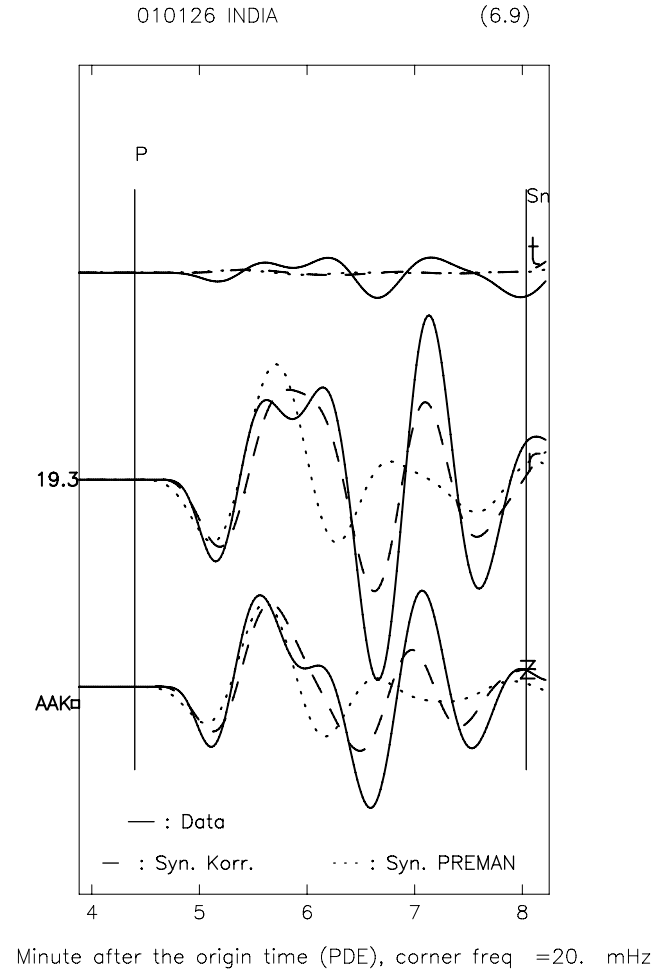

Gambar 5: Perbandingan seismogram terukur dengan sintetik dikoreksi untuk jendela waktu gelombang $\mathrm{P}$ di stasiun AAK, frek. sudut $20 \mathrm{mHz}$

sedangkan model bumi PREMAN memberikan gelombang $\mathrm{ScS}$ sintetik dengan amplitudo yang lebih lemah.

Gambar 5 menyajikan perbandingan seismogram pada jendela waktu gelombang $\mathrm{P}$ dan repetisinya. Kontribusi dari ketebalan kulit bumi $42 \mathrm{~km}$ dan struktur kecepatan S di upper mantle dengan gradien positif untuk $\beta_{h}$ memberikan efek yang terlihat sangat jelas pada $\mathrm{P}$ waveform. Waveform dengan frekuensi tinggi (lekukan di maksimum pertama, $6^{\prime}$ dari origin time gempa) disimulasikan dengan baik oleh seismogram sintetik dari model bumi dikoreksi. Seismogram sintetik mendekati dengan sangat baik pada waktu tiba dan jumlah osilasi, panjang waveform pada maksimum pertama. Ini disimulasikan dengan cukup baik, tidak hanya itu, maksimum kedua (menit 7) yang merupakan fase gelombang P repetitif(PP) pun ikut disimulasikan dengan baik. Sedangkan model bumi PREMAN memberikan sintetik dengan osilasi yang lebih pendek.

\section{KESIMPULAN}

Telah dilaksanakan perbandingan seismogram antara seismogram terukur dengan sintetik-sintetiknya dari dua model bumi standard (IASPEI91 dan PREMAN), menunjukkan deviasi yang nyata pada waveform gelombang permukaan Love. Hasil analisa menunjukkan bahwa perbedaan ketebalan kulit bumi diperjelas oleh waveform gelombang Love, walaupun orde dari panjang gelombangnya 7,5 kali lebih besar daripada 
beda ketebalan kulit bumi. Inilah keunggulan dari metoda analisa waveform dalam dimensi waktu dan ketiga komponen ruang secara simultan.

Untuk menyelesaikan diskrepansi yang dijumpai, digunakan ketebalan kulit bumi sebesar $42 \mathrm{~km}$ dan perubahan pada gradient kecepatan di upper mantle untuk mendapatkan fit- ting pada gelombang permukaan Love, dan koreksi negatif pada koefisien $\beta_{v}$ di upper mantle untuk mendapatkan fitting pada gelombang permukaan Rayleigh. Sedangkan untuk fitting pada gelombang $\mathrm{P}$ juga didapatkan, merupakan kontribusi dari perubahan ketebalan kulit bumi dan struktur kecepatan $\beta$ di upper mantle.
[1] Bagus J.S., 1999, Möglichkeiten und Grenzen der Modellierung vollständiger langperiodischer Seismogramme, Doktorarbeit, Berichte Nr. 12, Inst. für Geophysik, Uni. Stuttgart

[2] Dalkolmo, J. , 1993, Synthetische Seismogramme fuer eine sphärisch symmetrische, nichtrotierend Erde durch direkte Berechnung der Greenschen Funktion, Diplomarbeit, Inst. für Geophys., Uni. Stuttgart

[3] Bulland, R. and Chapman, C., 1983, Travel time Calculation, BSSA, 73, $1271-1302$

[4] Lévêque, J.J., Debayle, E. and Maupin, V., 1998, Anisotropy in the Indian Ocean upper mantle from Rayleigh and Love waveform inversion, Geophys. J. Int., 133, 529-540

[5] Debayle, E. and Lévêque, J.J., 1997, Upper mantle heterogeneities in the Indian Ocean from waveform inversion, Geoph. Res. Lett., 24, 245-248

[6] Dreger, D.S., 2002, Time-Domain Moment Tensor INVerse Code (TDMT_INVC), The Berkeley Seismological Laboratory (BSL), report number 8511

[7] Dziewonski, A.M. and Anderson, D.L., 1981, Preliminary reference Earth model, Phys. of the Earth and Plan. Int., 25, 297 $-356$

[8] Friederich W., 1997, Regionale, dreidimensionale Strukturmod- elle des oberen Mantel aus der wellentheoritischen Inversion teleseismischer Oberflächenwellen, Berichte des Instituts für Geophysik der Universität Stuttgart, 9

[9] Friederich, W. and Dalkolmo, J., 1995, Complete synthetic seismograms for a spherically symmetric earth by a numerical computation of the green's function in the frequency domain, Geophys. J. Int., 122, 537-550.

[10] Kennett, B.L.N., 1991, IASPEI 1991, Seismological Tables, Research School of Earths Sciences, Australian National University

[11] Mukhopadhyay and Kayal, 2003, Seismic Tomography Structure of the 1999 Chamoli Earthquake Source Area in the Garhwal Himalaya, Bull. of the Seism. Soc. of America, 93, $1854-1861$.

[12] Sheehan,A. F., Schulte, V. P., Gaspar, M. and de la Torre, T., 2006, Seismic Imaging Of The Himalayan Collision Zone, proposal pada "2006 IRIS 5-YEAR"

[13] Mitra, S., Russell, S., Priestley, K., Gaur, V.K. and Rai, S.S., 2002, Measurements of Frequency Dependent Lg Attenuation in India. Eos Trans. AGU, 83(47), Fall Meet. Suppl., Abstract S51B-1042, 2002. 